\section{Increased food consumption in thirsty rats after water satiation: Inhibition by salts*}

\author{
HARBANS LAL and JOSEPH ZABIK \\ Department of Pharmacology \& Toxicology \\ University of Rhode Island, Kingston, R.I. 02881
}

Thirsty rats gradually learned to eat excessively after water satiation. The excessive eating subsequent to water consumption was antagonized by one $\mathrm{M} \mathrm{NaCl}$ injection (IP) but not by an injection of distilled water.

The multiple mechanisms whereby rats regulate their food and water intake are obscure (Adolph, 1947). In the one aspect of water regulation, there is evidence that cellular dehydration (Corbit, 1965, 1968; Fitzsimons, 196 la; Gilman, 1937; Holmes \& Gregersen, 1950) and hypovolemia (Fitzsimons, 1961b; Oatley, 1964; Stricker, 1966) are stimuli for thirst. The experiment reported here suggests that dilution of plasma salts or water loading are stimuli for eating. In addition, these experiments were designed to test the hypothesis that the sudden dilution of the plasma produces a "motivational state" for excessive eating.

Previously, acute administration of water through intragastric tube (Smith et al, 1949) or single intravenous infusion of water (Smith, 1966) was shown to produce small increases in food consumption. However, these alternate methods of water loading are stressful and require extensive handling of the experimental Ss. Experiments herein described made use of spontaneous drinking in thirsty rats to introduce large amounts of water into the body.

\section{METHOD}

Thirty adult male Sprague-Dawley derived rats (Charles River Farms), weighing $350-400 \mathrm{~g}$ at the beginning of the experiment, were divided into three groups. Two groups (water-deprived experimental and water-deprived control) were deprived of water but allowed food ad lib. The third group was deprived of food and water. All animals were given premeasured quantities of food and water during the experimental session. The experimental sessions were run during the morning hours only in order to minimize the effect of circadian rhythm on hunger and thirst.

During the experimental session, the water-deprived experimental rats and the rats deprived of food and water were allowed free access to a measured quantity of distilled water for $30 \mathrm{~min}$. It was previously determined that approximately

*Editorial assistance of Donald Kissil in preparing this manuscript is greatly appreciated.
$25 \mathrm{~min}$ of drinking produced water satiation and that no further water consumption occurred. The water was then removed and a weighed quantity of food was placed in the otherwise clean cages for $60 \mathrm{~min}$. In water-deprived control rats, $30 \mathrm{~min}$ of water followed the $60 \mathrm{~min}$ of food after an interval of 2 to $4 \mathrm{~h}$. The water and food consumed by each rat was measured for each experimental session.

After the quantity of daily food consumption was stabilized, rats of each group were divided randomly into two subgroups. One of the subgroups was given injections (IP) of $3 \mathrm{ml}$ of distilled water, while the other subgroup was injected with $3 \mathrm{ml}$ of salt solution, ${ }^{1}$ prior to the $60 \mathrm{~min}$ of food availability. On the subsequent day, these treatments were repeated but reversed (i.e., the distilled-water subgroups were given salt solution, while the other subgroup received distilled water). The data from both subgroups were pooled after the two sequences of iniection were found not to differ from each other $(p>.05)$.

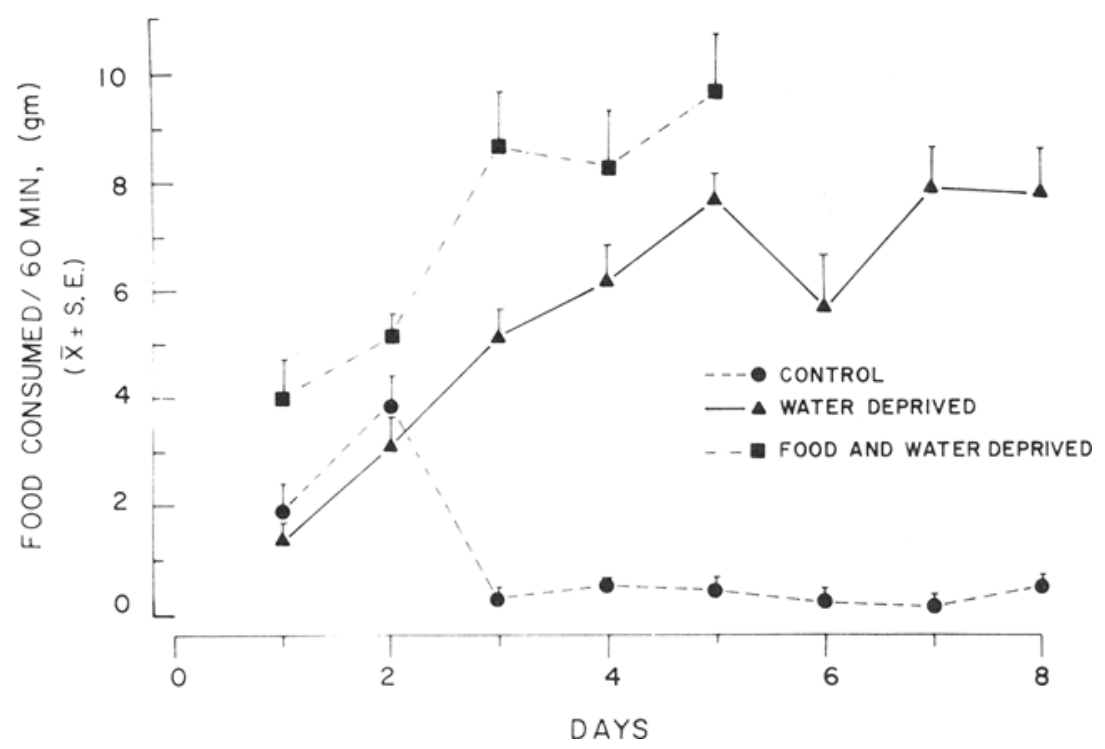

Fig. 1. Food consumed during $60 \mathrm{~min}$ after water satiation. The rats were deprived of water or water and food for $22 \mathrm{~h}$. Control rats were treated similarly to water-deprived rats except that, beginning on Day 3 , they were water satiated $2.4 \mathrm{~h}$ after $60 \mathrm{~min}$ of food.
In order to determine the effect of water satiation on food consumption, the latter was measured during the $60 \mathrm{~min}$ after water satiation daily throughout the experiment. There was no water satiation before $60 \mathrm{~min}$ of food in the control group except during the first 2 days. This group was run so that the food consumption due to hunger could be estimated under our experimental conditions in the rats that initially showed increased food intake after water satiation. For comparison, food and water consumption were measured for 5 days in six rats not deprived of water and food. On the average these rats consumed $0.04( \pm 0.01) \mathrm{g}$ of food and $2.3( \pm 0.66) \mathrm{ml}$ of water in $60 \mathrm{~min}$ of experimental period during the last 3 of the 5 days.

Data summarized in Fig. 1 show that, after water satiation, food consumption increased markedly in both of the experimental groups. The food consumption increased gradually intil it tripled by the 5 th day (Day 1 vs Day 5 , $\mathrm{p}<.005$ in both groups) in both experimental groups.

Data from two experimental groups summarized in Fig. 2 show that the rats deprived of water only, consumed more water than those deprived of both food and water $(p<.005$ in all three comparisons). The food consumption of those rats that were deprived of water only, was slightly less than the food consumption of those that were deprived of both food and water. The difference was significant only in the distilled-water group $(\mathrm{p}<.05)$. Injection of distilled water did not alter food consumption, but the 


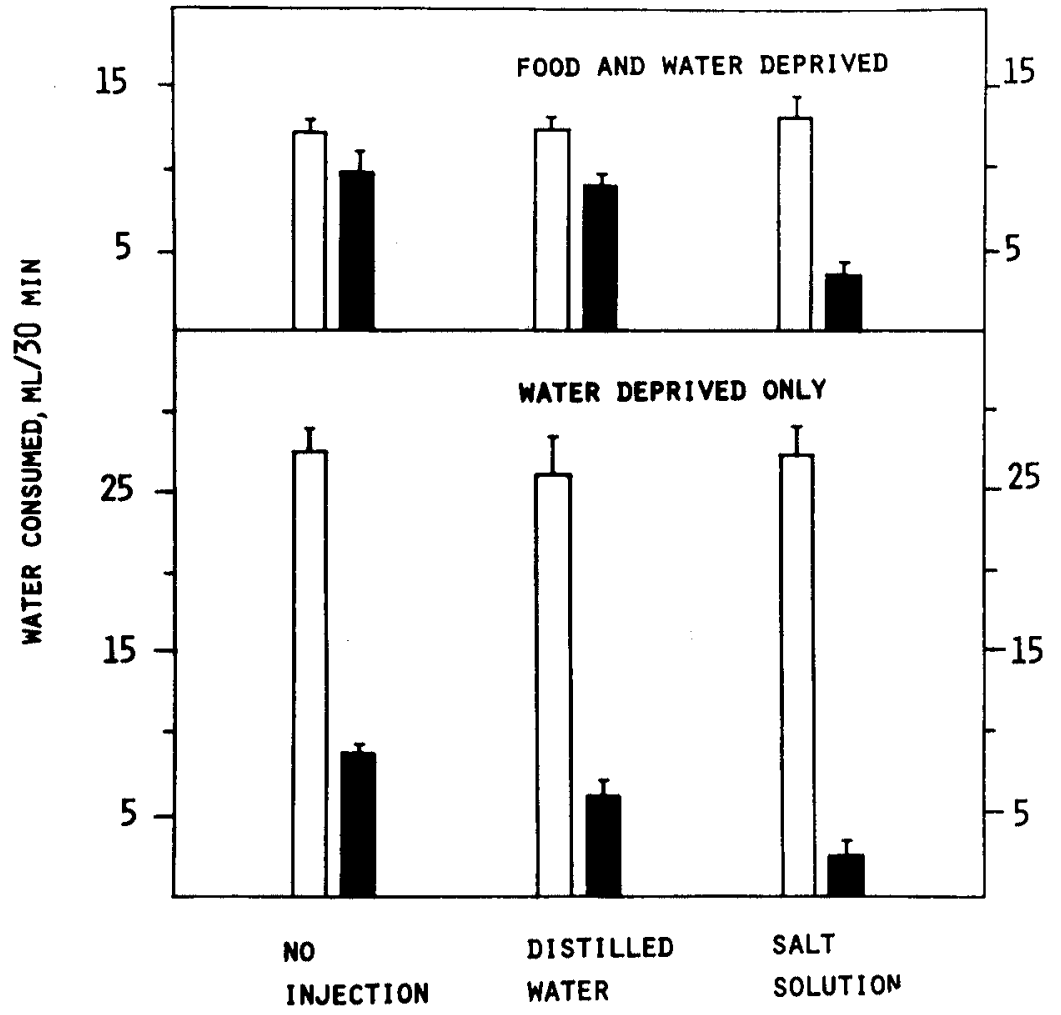

Fig. 2. Water and food consumed by two groups of rats. Food consumption was measured during $60 \mathrm{~min}$ after $30 \mathrm{~min}$ of free water.

injection of salt solution markedly decreased food consumption of the water-satiated rats in both groups $(\mathrm{p}<.01)$. Injection of distilled water or salt solution did not affect water consumption in either group of rats. In a separate experiment it was established that the injection of salt solution depressed operant lever pressing for not more than $3 \mathrm{~min}$. Thus injection of salt solution was not a disabling treatment in our experimental conditions.

\section{DISCUSSION}

Food and water deprivation increases significantly the serum sodium concentration (Stevenson et al, 1950), which is known to stimulate drinking (Kutscher, 1966), possibly through cellular dehydration and hypovolemia (Corbit, 1968). Water deprivation alone may further increase serum salts due to either the salt content of food ingested during that period or the decreased urine output to conserve water (Dicker \& Nunn, 1957), or both. Either would explain the greater stimulation of water drinking in water-only deprived rats.
Uninterrupted consumption of large quantities of water would be expected to result in the salt dilution of plasma that apparently triggered eating, since the injection of salt solution immediately after water consumption blocked this response. In our experiment the reduction in food consumption was not due to the discomfort of the IP injection, since drinking behavior was not depressed. Absence of the reduction of drinking behavior due to concentrated salt solution was also reported by Corbit (1968) without any sign of physical disability.

The progressive increase in food consumption with time indicates that the animals learned to eat in order to correct the physiological imbalance produced by excessive drinking. This learned behavior seems to depend upon the "motivational state" induced by plasma dilution. Eating on the first day could not elevate plasma tonicity instantaneously because of considerable delay in digestion and absorption processes. Thus, the lack of instantaneous feedback from eating, with regard to restoration of plasma tonicity, would require several trials, separated in time, in order for the animals to associate eating with eventual correction of the salt deficiency that was created by excessive drinking. In other words, ingestion of food served as secondary reinforcement for delayed availability of salt to the body.

It should be admitted that our data do not rule out the possibility of osmotically induced cellular hydration acting as a stimulus for eating, instead of salt deficiency acting by itself as an eating stimulant.

\section{REFERENCES}

ADOLPH, E. F. Urges to eat and drink in the rat. American Journal of Physiology, 1947, 151 , $110-125$.

CORBIT, J. D. Effect of intravenous sodium chloride on drinking in the rat. Journal of Comparative Physiological Psychology, 1965, $60,397-406$.

CORBIT, J. D. Cellular dehydration and hypovolemia are additive in producing thirst. Nature, 1968, 218, 886-887.

DICKER, S. E., \& NUNN, J. The role of the anti-diuretic hormone during water deprivation in rats. Journal of Physiology, 1957, 136, 235-248.

FITZSIMONS, J. T. Drinking by nephrectomized rats injected with various substances. Journal of Physiology, 1961a, 155, 563-579.

FITZSIMONS, J. T. Drinking by rats depleted of body fluid without increase in osmotic pressure. Journal of Physiology, 1961b, 159, 297-309.

GILMAN, A. The relation between blood osmotic pressure, fluid distribution and voluntary water intake. American Journal of Physiology, 1937, 120, 323-328.

HOLMES, J. H., \& GREGERSEN, M. I. Observations on drinking induced by hypertonic solutions. American Journal of Physiology, 1950, 162, 326-337.

KUTSCHER, C. Effect of hypertonic saline injections and water deprivation on drinking, serum osmolality and gut water. Physiology \& Behavior, 1966, 1, 259-268.

OATLEY, K. Changes in blood volume and osmotic pressure in the production of thirst. Nature, 1964, 202, 1341-1342.

SMITH, M. Effect of intravenous injections on eating. Journal of Comparative \& Physiological Psychology, 1966, 61, 11-14.

SMITH, M., POOL, R., \& WEINBERG, H. The effect of peripherally induced shifts in water balance on eating. Journal of Comparative \& Physiological Psychology, 1949, 52, 115-120.

STEVENSON, J. A. F. WELT, L. G. \& ARLOFF, J. Abnormalities of water and electrolyte metabolism in rats with hypothalmic lesions. American Journal of Physiology, 1950, 161, 35-39.

STRICKER, E. M. Extracellular fluid volume and thirst. American Journal of Physiology, 1966, 211, 232-238.

\section{NOTE}

1. Each mililiter of the salt solution contained: $\mathrm{NaCl}, 60 \mathrm{mg} ; \mathrm{KCl}, 0.075 \mathrm{mg} ; \mathrm{CaCl}_{2}$, $0.1 \mathrm{mg} ; \mathrm{NaHCO}_{3}, 1.0 \mathrm{mg}$. 